\title{
“Doctor, please don't say he died by suicide": exploring the burden of suicide survivorship in a developing country
}

\author{
Samuel Robsam Ohayi®
}

\begin{abstract}
Background: Annually, 800, 000 die from suicide worldwide. However, suicide is believed to be rare in our environment. Suicide causes significant life disruptions in people bereaved by it. These disruptions result from associated complicated grieving pattern characterised by stigma, feeling of shame, responsibility, guilt, etc. People therefore usually want to be certain that their relation indeed died from suicide. Being certain can in part help survivors achieve closure. A pathologist is often called upon to diagnose the actual cause of death in suspected suicide. The aim of this paper is to highlight the perception and attitude of survivors to suicide in our environment.

Methods: This is a prospective study carried out in Enugu State University Teaching Hospital, Enugu, Nigeria. Data was obtained by audio-recording and transcription of face-to-face interviews of 8 groups of relatives who had presented to the pathologist for autopsy of their relation suspected to have committed suicide. Transcribed data was double checked for accuracy and analysed. Informed consent was obtained from participants. Ethical clearance was obtained from the Ethical Committee of the hospital.
\end{abstract}

Results: There were 8 cases of suspected suicide over a 7-year period accounting for $0.6 \%$ of all violent deaths in the period. The central attitude of survivors in all the cases was denial of the event. At all the meetings survivors desired the pathologist to report cause of death differently than suicide. Also, in all cases, the extended family felt affected by the event. The following six themes in descending order of importance were identified to underlie survivors' attitude to suicide: fear of stigma and its consequent isolation, fear of economic repercussions, a conflict of choice of cause of death stemming from religious beliefs about the afterlife, feeling of shame and anger against the deceased and fear that acknowledging the event may bring a repeat in the family.

Conclusion: There is profound fear of stigma and associative concerns which leads to outright suicide-denial. There is a need to educate the society about the reality and dynamics of suicide. This will make a bereaved person open to receiving requisite care.

Keywords: Suicide, Suicide survivor, Perception, Attitude, Complicated grieving, Stigma

\section{Background}

Suicide is a public health problem. It is among the thirteen leading causes of death worldwide (DeLeo et al. 2002). According to World Health Organization (WHO) (2014) estimates, it is more prevalent with increasing age and more common in males than females accounting for $50 \%$ and $71 \%$ of violent deaths in men and women respectively. There are approximately 800,000 suicide

Correspondence: robohayi@yahoo.com

Department of Histopathology, Enugu State University Teaching Hospital \& College of Medicine, Parklane, Enugu, Nigeria deaths annually with a global age-standardised rate estimated at 11.4/100,000 population (WHO 2014). Rates vary considerably among nations the highest being reported from Eastern Europe while lowest rates are from Latin America and parts of Asia (DeLeo et al. 2002). The rate for Nigeria is estimated at 5.0-9.9/100,000 populations (WHO 2014). The most common means used to procure suicide include firearm, hanging, poisoning, jumping from a height, vehicular impact, drowning, severance of vessels and electrocution (WHO 2014; Young et al. 2012). 
Suicide causes significant life disruptions for its survivors. The number of persons affected by each suicide event appears to depend on sociocultural circumstances of those involved by the suicide with various authors reporting between as low as 18 and as high as 50 (Drapeau and McIntosh 2015; Bernan 2011; Bland 1994). These disruptions stem mainly from prolonged grieving that is associated with suicide. This has been called complicated grieving patterns and has several components which include feeling of stigma, shame, responsibility, and guilt. Complicated grieving predisposes affected people to an increased risk for major depression, posttraumatic stress disorder and suicidal behaviours (Young et al. 2012; Pitman et al. 2016).

Diagnosing a particular death event as a suicide is not straightforward as may be assumed. Suicide has been defined by WHO as "the act of killing oneself, deliberately initiated and performed by the person in the full knowledge or expectation of its fatal outcome." (WHO 2001). Or, according to the 1973 edition of the Encyclopedia Britannica as quoted by Shneidman (1985), suicide is "the human act of self-inflicting one's own life cessation." Central to the idea of suicide is the intent to end one's own life by oneself. However, it is difficult to establish that a dead person actually intended to end his life if he had not left a suicide note or made definite statements about such intentions to people before his death. Yet, even if one or both was done before an individual's death, it is difficult to make a correlation between the declared intent and the outcome. This may apply to deaths from drug overdose or refusal to take prescribed drugs, vehicular impact and other reckless behaviours. Nevertheless, a death can be diagnosed as suicide if the circumstances are consistent with suicide provided that murder, accident and natural causes can be ruled out (DeLeo et al. 2002). The pathologist has the onerous role of establishing this diagnosis of cause of death as in other cases of unexplained death which are known as coroner cases in some countries including Nigeria. Dead bodies following deaths from such circumstances are transmitted to the pathologist by the police. It is usual that after autopsy, the pathologist should communicate his findings, including cause of death, to the police as well as the relations of the deceased. Such information is important to the bereaved family in helping them achieve closure. In our environment, however, a diagnosis of suicide appears not to achieve this purpose.

Suicide is believed to be rare in our environment but encounters with people bereaved by suspected suicide suggest differently. The aim of this paper is to highlight the perception of and attitudes to suicide by people bereaved by suicide and therefore call the attention of policymakers towards the need for support for people bereaved by suicide also known as suicide survivors.

\section{Methods}

This is a prospective study that involved the use of a qualitative approach and thematic analysis. Study subjects were relatives of persons suspected to have committed suicide who with the police had approached the pathologists at the Forensic Unit of the Department of Histopathology of a University Teaching Hospital to perform autopsy on the body of the person suspected to have committed suicide. The study covered the Enugu State of Nigeria which according to the 2016 estimates of the National Population Commission and Nigerian National Bureau of Statistics has a population of 4,411, 119 people and a population density of $616.0 / \mathrm{km}^{2}$. The state is in the Eastern part of Nigeria and inhabited predominantly by Igbos. The population has a high literacy level, is very religious and engaged mostly in civil service jobs, commerce and farming.

The police upon receiving report of a death of questionable and unnatural circumstances including suspected suicide, in compliance with the state's coroner law (Coroners Act of 1958, laws of the Federation of Nigeria and Lagos, Cap 41 n.d.), reports such death to a state-appointed coroner (via form B of the Coroner's Ordinance Cap. 41). The coroner then authorises the pathologist in the Forensic Unit (via form $\mathrm{C}$ of the Coroner's Ordinance Cap. 41) to perform an autopsy on the body of the deceased to determine the actual cause and circumstance of death. The police thereafter deliver such a body to the unit pathologists for autopsy and also guide the bereaved family to the pathologist who subsequently holds meetings with the family. The primary purpose of such meetings is for the pathologist to get all possible relevant history from the dead person's survivors especially those who lived or interacted with him around the period leading to the suspected suicide event.

The participants came in 8 groups one for each of the 8 cases of suspected suicide encountered in the period of the study. Data were collected during face-to-face meetings between the pathologist and these groups before and after an autopsy was performed. For proper identification, the suspected suicide events and therefore the deceased were numbered according to the order in which they came, namely G1 to G8, while the family/ group members, i.e. study participants which ranged from 2 to 5 people, were numbered as P1 to P5 as the case may be. This, for an instance, gave a composite number for participant number one of group one as G1P1. Participants included family members, non-family community members and church members. The pathologist was not involved in selecting the members of any of the groups including determining their number.

There was a total of 13 meetings before autopsy and 6 meetings after autopsy prior to issuing a report. The average time between a suspected suicide event 
and the first meeting between the participants and the pathologist was 5 weeks and 3 days. The range of time spent per meeting was 32 to $61 \mathrm{~min}$. Apart from the first meeting brought about by the police, other meetings held at the instance of the bereaved family. Each meeting was held with all present members of a group together in one place at a time. Members of each group converged on most issues so that opinions expressed by individual participants usually reflected a group's view. The police was not part of any of the meetings. All meetings were held at the pathologist's office. The period during which autopsy report was issued was not counted as one such meeting in the cases in which a bereaved family was around. Each session was audio-recorded with permission of the group in attendance with the understanding that such recordings were for research and would not be used for any other purpose. Meetings took the form of semi-structured discussions during which each person was at liberty to share his concerns and make requests. When necessary during the meetings, the pathologist asked questions which were mostly open-ended. Audio-recordings of the meetings were transcribed by persons trained in that. The transcription was read and re-read and when necessary was read while listening to the recording. The recurring concerns were distilled and thematically analysed. Telephone and informal conversations were not regarded as meetings and as such deliberations at such occasions were not recorded. Informed consent was obtained from participants and they were assured of the confidentiality of data obtained and also that they reserve the right to withdraw from the study at any point. Ethical clearance was obtained from the Ethical Committee of our hospital.

\section{Results}

There were 8 reported cases of suspected suicide over a 7 -year period accounting for $0.6 \%$ of all violent deaths in the period. There were altogether 27 participants in the study made up of 24 (88.9\%) males and $3(11.1 \%)$ females with an age range of 22 to 51 years. The lowest level of education among the participants was primary (elementary) while the highest was tertiary (postsecondary/higher education).

Participants included family members, non-family community members and church members. Each group of participants was composed of people who lived in the villages and cities though in no particular proportion. Table 1 shows the sociodemographic characteristics of the participants in the study while Table 2 shows the characteristics of the deceased all of who were males and with an age range of 23 to 72 years. Representative groups for all 8 cases claimed that immediate and extended families of a native of their community who died by suicide will be directly affected by various disruptive consequences associated with a suicide event. In addition, 3 (37.5\%) of the families/groups said that some of such consequences, e.g. religion-associated consequences, will affect the entire village albeit in milder measure. This study identified that the central attitude of participants to suicide is denial of the suicide event. Five core themes were identified as being responsible for this attitude of survivors namely fear of stigma and its consequent isolation, fear of economic repercussions, fear of religious consequences and beliefs about afterlife, feeling of shame and anger against the deceased. In all of the meetings, each group of the 8 groups of participants (suicide survivors) desired the pathologist to report the cause of death differently than as suicide. No group said that they recovered a suicide note or gave a history that their relative spoke or acted in a way to suggest an intent to take their life in the period leading to the suicide event. Also, no group gave a history of completed or attempted suicide in the family of the deceased prior to the index event.

\section{Discussion}

\section{Denial of suicide}

From this study, the central attitude of those bereaved by suicide to suicide is an outright unwillingness to accept that the death of a relative was due to suicide. During each meeting with the pathologist, each of the 8 groups in various ways tried to persuade the pathologist not to report the cause of death as suicide. This position is summed up by one participant as follows:

Doctor, please don't say he died by suicide. We cannot allow the world hear that. No, doctor, please, nobody must hear that. You can say anything but ... please just don't say that. (Participant G5P1)

Though 3 (37.5\%) bereaved families felt that they had good reason(s) to believe that their relation did not commit suicide, interestingly, neither they nor any other group made any attempt to hinge their denial of the suspected suicide event on a tangible evidence. Rather the main concern expressed by all the groups was that those bereaved be shielded from the life disruptions association with suicide bereavement. The following excerpts from participants highlight this fact:

We were not with him. We don't know what he did or did not do.... What is the use of creating more trouble...everybody will just suffer for what a person who chose to leave them did? (Participant G3P2)

Do you know what it can mean...to go tell everybody that our brother killed himself? If you knew...We cannot do that. (Participant G1P1)

Other authors (Tzeng et al. 2010; Avrami 2005) also reported denial of the event by participants in their 
Table 1 Sociodemographic characteristics of participants

\begin{tabular}{|c|c|c|c|c|c|c|c|}
\hline Group & Number & Age (in years) & Sex & Church affiliation (denomination) & Education $^{*}$ & Employment & Relationship with the deceased \\
\hline \multirow[t]{4}{*}{ G1 } & G1P1 & 48 & Female & Catholic & Tertiary & Civil service & Sister \\
\hline & G1P2 & 22 & Male & Catholic & Secondary & Artisan & Nephew \\
\hline & G1P3 & 34 & Male & Catholic & Tertiary & Corporate & Cousin \\
\hline & G1P4 & 40 & Male & Evangelical & Secondary & Trading & Brother \\
\hline \multirow[t]{3}{*}{ G2 } & $\mathrm{G} 2 \mathrm{P} 1$ & 39 & Male & Catholic & Primary & Farming & Son \\
\hline & G2P2 & 47 & Male & Catholic & Secondary & Civil service & Son \\
\hline & G2P3 & 33 & Male & Catholic & Secondary & Artisan & Nephew \\
\hline \multirow[t]{3}{*}{ G3 } & G3P1 & 45 & Male & Pentecostal & Tertiary & Civil service & Church member \\
\hline & G3P2 & 43 & Male & Evangelical & Secondary & Trading & In-law \\
\hline & G3P3 & 48 & Female & Evangelical & Secondary & Artisan & Sister \\
\hline \multirow[t]{5}{*}{ G4 } & G4P1 & 50 & Male & Catholic & Secondary & Artisan & Son \\
\hline & G4P2 & 48 & Male & Evangelical & Tertiary & Trading & Son \\
\hline & G4P3 & 51 & Male & Pentecostal & Secondary & Civil service & Community member \\
\hline & G4P4 & 35 & Male & Catholic & Primary & Civil service & Nephew \\
\hline & G4P5 & 44 & Male & Catholic & Primary & Farming & Nephew \\
\hline \multirow[t]{3}{*}{ G5 } & G5P1 & 45 & Male & Jehovah's Witness & Tertiary & Corporate & Church member \\
\hline & G5P2 & 50 & Male & Jehovah's Witness & Secondary & Trading & Brother \\
\hline & G5P3 & 55 & Male & Catholic & Secondary & Artisan & Brother \\
\hline \multirow[t]{4}{*}{ G6 } & G6P1 & 44 & Male & Catholic & Tertiary & Civil service & Community member \\
\hline & G6P2 & 47 & Male & Pentecostal & Secondary & Farming & Uncle \\
\hline & G6P3 & 43 & Female & Evangelical & Tertiary & Trading & Aunt \\
\hline & G6P4 & 28 & Male & Catholic & Primary & Civil service & Brother \\
\hline \multirow[t]{2}{*}{ G7 } & G7P1 & 25 & Male & Evangelical & Secondary & Trading & Son \\
\hline & G7P2 & 39 & Male & Pentecostal & Tertiary & Corporate & Brother \\
\hline \multirow[t]{3}{*}{ G8 } & G8P1 & 37 & Male & Catholic & Secondary & Artisan & Nephew \\
\hline & G8P2 & 41 & Male & Catholic & Secondary & Civil service & Brother \\
\hline & G8P3 & 47 & Male & Catholic & Primary & Farming & Brother \\
\hline
\end{tabular}

"Primary: elementary; secondary: high school; tertiary: postsecondary/higher education including University, Polytechnic, College of Education, etc.

studies. Nic an Fhaili et al. (2016) reported that some participants in their study though accepted suicide as a mode of their relative's mode but preferred the use of the expression "died by suicide" rather than "committed suicide." These relatives believe that "committed" implied a crime and therefore amplified the stigma they felt. Participants in this present study said their desire for a different diagnosis than suicide is also reinforced by the fact that the law will not hold anybody responsible for the act. One participant puts it this way:

Table 2 Sociodemographic characteristics of the deceased

\begin{tabular}{|c|c|c|c|c|c|c|c|c|}
\hline Number & Sex & Age (years) & Marital status & Children & Church affiliation (denomination) & Occupation & Place of abode & Method of suspected suicide \\
\hline G1 & Male & 45 & Married & No & Catholic & Trading & Urban & Hanging \\
\hline G2 & Male & 66 & Married & Yes & Catholic & Farming & Rural & Hanging \\
\hline G3 & Male & 52 & Married & Yes & Pentecostal & Trading & Urban & Hanging \\
\hline G4 & Male & 72 & Widowed & Yes & Catholic & Farming & Semi-rural & Hanging \\
\hline G5 & Male & 62 & Married & Yes & Jehovah's Witness & Civil service & Urban & Hanging \\
\hline G6 & Male & 23 & Single & No & Catholic & Apprentice & Urban & Hanging \\
\hline G7 & Male & 49 & Married & Yes & Non-specific & Civil service & Urban & Hanging \\
\hline G8 & Male & 54 & Single & Yes & Catholic & Artisan & Semi-rural & Poisoning \\
\hline
\end{tabular}


If a man kills another, the law punishes him. What of the man who kills himself? The law does nothing but abandon the living to the punishment. Participant G5P1

\section{Fear of stigma}

Stigmatisation of suicide has always been with man. It is demonstrated through various combinations of the following practises namely denying the deceased proper burial, excommunication of the bereaved family from the community and appropriation of the property of such family as a whole or those of the deceased (Scocco et al. 2012). Stigmatisation is described as a social process that involves labelling, stereotyping and rejecting human differences with the intent to exert social control (Link and Phelan 2001; Parker and Aggleton 2003). Suicide stigmatisation in our culture is aptly captured by Achebe (1984) in his foremost novel "Things fall apart" when Obierika speaking to the District Commissioner about the suicide of his friend, Okonkwo, said, "We cannot bury him. Only strangers can. That man was one of the greatest men in Umuofia. You drove him to kill himself; and now he will be buried like a dog...." Fear of stigmatisation was a dominant theme in all the meetings with bereaved families/groups in this study. It was proffered by all eight families as the major reason they did not want a diagnosis of suicide pronounced on their relation. Groups however varied in the content of the stigmatisation they feared. This included denial of proper burial rites $(n=8 ; 100 \%)$, refusal to be accepted in marriage $(n=7 ; 87.5 \%)$ and non-acceptance into the traditional institutions of their community $(n=5 ; 62.5 \%)$. Additionally, 3 families each (37.5\%) said that they feared shunning/denial of routine social contacts and banning from participating in economic activities respectively. These fears are reflected in the following excerpts:

If you commit suicide in our place, you will be treated like a dog...like you are a curse. They will just dig the ground under where you are hanging and cut you into it. And your family, nobody from you can marry anybody from there ever again. (Participant G2P3)

If it is believed in the community that my brother killed himself, I have 2 sons...People will take a long time before they can do anything with us again. We can't take the Ozo title [admission into traditional society] ever again. (Participant G4P5)

This finding that fear of stigmatisation is a major concern for suicide survivors is also documented in a number of studies (Young et al. 2012; Pitman et al. 2016;
Scocco et al. 2012; Peters et al. 2016). Also, all the participants in this study similar to those in other studies (Nic an Fhaili et al. 2016; Hanschmidt et al. 2016) said they would not accept any form of help with respect to the event. One participant (G3P1) put it succinctly as follows:

Help...for what? If you say, "I need help" what are you not saying? Give me all these side talks, finger pointing! It means that I agree that my relation hanged himself. (Participant G3P1)

\section{Feeling of shame}

Like the fear of stigmatisation, all participants said they already felt shamed by the suspected suicide and would face even greater shame if suicide is confirmed. This pattern of shame co-occurring with stigma in suicide bereavement has also been reported by other workers (Pitman et al. 2016; Peters et al. 2016; Asare-Doku et al. 2017). According to participants in this study, suicide would bring shame to their family for one or a combination of the following reasons:

- Confirmed suicide by a family member will suggest that their family relationships are dysfunctional $(n=$ 4; 50\%)

- They will be looked upon as a family that is cursed $(n=3 ; 37.5 \%)$

- Confirmed suicide by a family member will suggest that they are a family of weaklings who are unable to endure the pressures of life $(n=6 ; 75 \%)$

- The community shall start referring to them as "the family of people who kill themselves" ( $n=3 ; 37.5 \%)$

Shame appears to reduce the sense of being worthy of any help and, like fear of stigmatisation, appears to be central to poor help-seeking behaviour that was demonstrated by all participants in this study. Pitman et al. (2016) also found a positive relationship between feeling of shame and poor help-seeking attitude in suicide survivors. Participant G8P2 said that suicide shame would be far reaching.

With just suspicion, we are already the wastebasket of our community... Never be able to lift our voice at anybody or on any issue. Oh, they will just ignore you if you try to put your mouth into any issue... People will say, "No, don't say anything to them. You won't know what you say that will make them go kill themselves." If any of us now will even go to the hospital for anything, people will say that another of their brother wanted to kill himself. (Participant G8P2) 


\section{Fear of economic repercussions}

Six $(75 \%)$ of the 8 families said that if people knew that their relative committed suicide, they would suffer definite and severe economic repercussions. All 6 families (75\%) said that they would be required to carry out expensive rituals for the cleansing of the land. Five of them $(62.5 \%)$ said that the property in which the suicide act was performed would be forfeited to $a n i$, the earth goddesses, while $50 \%(n=4)$ said that they will not be able to transact business in the community. Scocco et al. (2012) also reported that suicide survivors in their study reported similar economic consequences. However, not all economic repercussions are brought on survivors by the society. Two family groups $(25 \%)$ said that they would not appropriate any material thing left behind by their dead relative if his death were pronounced to be due to suicide even if there is no traditional requirement for them to do so. In their belief, doing that could bring them economic difficulties or even lead to suffering similar fate as the deceased. Participant G4P2 said:

It is better you don't know... what you know not doesn't kill you. If you know...the man killed himself and you take his property? You can't do that because it will bring curse upon your own. (Participant G4P2)

In contrast though, some studies (Yang and Lester 2007; Stack 2007) believe that suicide may indeed be beneficial to society citing savings from not having to treat depression and other psychiatric conditions in people who commit suicide, pensions, social security and nursing home payments and assisted suicide, though the studies reportedly did not consider the cost of the psychological pains and suffering of suicide survivors.

\section{Religious concerns and beliefs about afterlife}

All the bereaved persons in this study subscribe to the Christian religion. Members of the same groups differed in their perception of the place of religion in dealing with suicide. Most $(n=21 ; 77.8 \%)$ participants in the discussions believed that suicide was sinful while some $(n=15$; $55.6 \%$ ) believed that if their relation had committed suicide, he must have been driven to the act by some evil forces. Hagaman et al. (2013) reported similar sentiments by suicide survivors in Haiti while Manoranjitham et al. (2007) reported that Indians accept suicide as an option to escape life challenges even though their religions put high values on life. Participants $(n=5 ; 67.5 \%)$ in this study feared that potential consequence of suicide would be refusal by the church to accord the dead appropriate burial rights a sentiment similar to that reported by Peters et al. (2016). Another expressed fear was that since it is the gods that drive people into killing themselves they may do it again to other family members $(n=3 ; 37.5 \%)$. Asked how denying suicide can prevent that, one participant answered as follows:

When you accept something, your chi (personal god) will accept that too. Participant G2P2

However, 5 groups (62.5\%) in addition expressed a conflict between wanting to appease the spirit of the dead and not wishing to desecrate the land. One family leader said:

We want to give our brother proper burial rights because otherwise his spirit will never rest; it will continue to stalk us. But we also don't want to bury him if he committed the act lest we desecrate the land and incur the anger of the gods. It is our dilemma. (Participant G7P1)

No participant expressed any concern that there could be a direct repercussion on his religious life or that of the other survivors in general following a suicide act.

\section{Survivors' anger against someone who died by suicide} Four $(50 \%)$ of the families expressed various degrees of anger at the dead relative while the other 4 said they would not speak against the dead. Of the families that felt anger, there was no unanimity on being angry and on the reasons for such anger. Three specific areas were identified as the basis on which the bereaved would feel anger against their relation who committed suicide. These include that the deceased abandoned family responsibilities (general and personal), that the deceased brought shame to the family and that the deceased action amounted to economic loss to the family. Survivor anger has been reported in other works (Young et al. 2012; Asare-Doku et al. 2017) though the reasons for the anger were different namely that the deceased deprived the survivor the opportunity to help him go through their challenging experiences and that the deceased was cowardly, unable to face life challenges.

\section{Limitations}

Because of the sampling method, participants in this study were only those recently bereaved by suspected suicide and were therefore in the acute phase of bereavement during the interview periods. Armed with only the information about how suicide is viewed in their culture and with no significant intervening period and events, e.g. burial of the dead between the suspected suicide event and time of interview which may have moderated their response to suspected suicide, the reported outcome may only apply to those in the acute phase of suicide bereavement. This limitation could be corrected for if people who had survived suicide for longer periods 
were also interviewed. Secondly, due to the small sample size, causal relationships could not be established.

\section{Conclusion}

Suicide survivors structure suicide narrative in a self-preservationist manner and therefore outrightly deny that the incident occurred. They actively seek to get this position corroborated by other persons including the doctor who perform the post mortem examination on such cases. This stems from a deep fear of the consequences that they believe await suicide survivors in the society. There is therefore need to educate the society about the reality and dynamics of suicide. This will help the larger society to show empathy to suicide survivors and therefore help people acknowledge the event if it happens and therefore seek help as it may become necessary.

\section{Abbreviations}

WHO: World Health Organization

\section{Acknowledgements}

The author wishes to acknowledge Mr. Ebuka Onyia and Mrs. Ugwuani Patty for their help with recording and transcribing the interviews.

\section{Author's contribution}

SRO solely conceptualised and carried out the work. The author read and approved the final manuscript.

\section{Funding}

The author received no funding for this work.

\section{Availability of data and materials}

Datasets generated during the current study are available from the author on reasonable request.

\section{Competing interest}

The author declares that he has no competing interests.

\section{Ethics approval and consent to participate}

Informed consent was obtained from the participants and ethical approval obtained from the ESUTH Teaching Hospital Ethical Committee.

\section{Consent for publication}

Not applicable

Received: 19 February 2019 Accepted: 28 July 2019

Published online: 08 August 2019

\section{References}

Chinua Achebe (1984) reprint. Things fall apart. Heinemann educational books, London.

Asare-Doku W, Osafo J, Akotia CS (2017) The experiences of attempt survivor families and how they cope after a suicide attempt in Ghana: a qualitative study. BMC Psych. 17:178. https://doi.org/10.1186/s12888-017-1336-9

Avrami S (2005) "I wish he had died in the war": suicide survivors-the Israeli case. Omega (Westport) 51:65-75. https://doi.org/10.2190/DGWU-PMLM-5J3Y-J7LL

Bernan AL (2011) Estimating the population of survivors of suicide: seeking an evidence base. Suicide Life Threat Behav 41(1):110-116

Bland D (1994) The experiences of suicide survivors 1989-June 1994. Baton Rouge Crisis Intervention Center, Baton Rouge

DeLeo D, Bertolote J, Lester D (2002) Self-directed violence. In: Krug EG, Dahlberg LL, Mercy JA, Zwi AB, Lozano R (eds) World Report on Violence and Health. World Health Organization, Geneva, pp 185-212

Drapeau CW, McIntosh JL (2015) U.S.A. suicide 2014: Official final data. American Association of Suicidology, Washington, DC http://www.suicidology.org/. Accessed 8 Dec 2018
Coroners Act of 1958, laws of the Federation of Nigeria and Lagos, Cap 41. Hagaman AK, Wagenaar BH, McLean KE, Kaiser BN, Winskell K, Kohrt BA (2013) Suicide in rural Haiti: clinical and community perceptions of prevalence, aetiology, and prevention. Soc Sci Med 83:61-69. https://doi.org/10.1016/j. socscimed.2013.01.032

Hanschmidt F, Lehnig F, Riedel-Heller SG, Kersting A (2016) The stigma of suicide survivorship and related consequences: a systematic review. PLoS One 11(9): 1-16. https://doi.org/10.1371/journal.pone.0162688

Link BG, Phelan JC (2001) Conceptualizing stigma. Annu Rev Sociol 27:363-385. https://doi.org/10.1146/annurev.soc.27.1.363

Manoranjitham S, Charles H, Saravanan B, Jayakaran R, Abraham S, Jacob KS (2007) Perceptions about suicide: a qualitative study from Southern India. Natl Med J India 20(4):176-179

Nic an Fhaili M, Flynn NJ, Dowling S (2016) Experiences of suicide bereavement: a qualitative study exploring the role of the GP. Br J Gen Pract:e92-e98. https://doi.org/10.3399/bjgp16X6834413

Parker R, Aggleton P (2003) HIV and AIDS-related stigma and discrimination: a conceptual framework and implications for action. Soc Sci Med 57:13-24. [PubMed]

Peters K, Cunningham C, Murphy G, Jackson D (2016) "People look down on you when you tell them how he died": qualitative insights into stigma as experienced by suicide survivors. Int J Ment Health Nurs 25(3):251-257. https://doi.org/10.1111/inm.12210

Pitman AL, Osborn DPJ, Rantell K, King MB (2016) The stigma perceived by people bereaved by suicide and other sudden deaths: a cross-sectional UK study of 3432 bereaved adults. J Psychosom Res 87:22-29. https://doi.org/1 0.1016/j.jpsychores.2016.05.009

Scocco P, Castriotta C, Toffol E, Preti A (2012) Stigma of Suicide Attempt (STOSA) scale and Stigma of Suicide and Suicide Survivor (STOSASS) scale: Two new assessment tools. Psychiatry Res 200:872-878. doi: https://doi.org/10.1016/j. psychres.2012.06.033 [PubMed]

Shneidman E (1985) Definition of suicide. Wiley, New York

Stack S (2007) Societal economic costs and benefits from death: another look. Death Stud 31(4):363-372. https://doi.org/10.1080/07481180601187217

Tzeng W-C, Su P-Y, Tzeng N-S, Yeh C-B, Chen T-H, Chen C-H (2010) A moral life after a suicide death in Taiwan. Qual Health Res 20:999-1007. doi: https://doi. org/10.1177/1049732310365503 [PubMed]

WHO (2001) The world health report. Burden of mental and behavioural disorders. www.who.int/whr/2001/chapter2/en/index6.html. Accessed 8 Dec 2018.

WHO (2014) Preventing suicide: a global imperative. Geneva: World Health Organization. http://apps.who.int> iris>handle. Accessed 17 Dec 2018

Yang B, Lester D (2007) Recalculating the economic cost of suicide. Death Stud 31(4):351-361. https://doi.org/10.1080/07481180601187209

Young IT, Iglewicz A, Glorioso A, Lanouette N, Seay K, llapakurti M, Zisook S (2012) Suicide bereavement and complicated grief. Dialogues Clin Neurosci. 14(2):177-186

\section{Publisher's Note}

Springer Nature remains neutral with regard to jurisdictional claims in published maps and institutional affiliations.

\section{Submit your manuscript to a SpringerOpen ${ }^{\circ}$ journal and benefit from:}

- Convenient online submission

- Rigorous peer review

- Open access: articles freely available online

High visibility within the field

- Retaining the copyright to your article

Submit your next manuscript at $\boldsymbol{\nabla}$ springeropen.com 